\title{
New WHO Europe Action Plan to fight MDR-TB
}

Eurosurveillance editorial team (eurosurveillance@ecdc.europa.eu) ${ }^{1}$

1. European Centre for Disease Prevention and Control (ECDC), Stockholm, Sweden

Citation style for this article:

Eurosurveillance editorial team. New WHO Europe Action Plan to fight MDR-TB.

Euro Surveill. 2011;16(37):pii=19967. Available online: http://www.eurosurveillance.org/ViewArticle.aspx?Articleld=19967

As the multidrug- and extensively drug-resistant tuberculosis (M/XDR-TB) is spreading at alarming rates in the World Health Organization (WHO) European Region - about 81,000 (18.4\%) of the estimated 440,000 patients worldwide with MDR-TB are considered to live in this region - the WHO Regional Office for Europe has launched an action plan to contain the spread of drug. resistant TB in the region by the end of $2015[1,2]$. This action plan was endorsed on 15 September 2011 by all 53 countries of the WHO European Region [3].

The plan has been prepared in consultation with representatives of the 53 countries of the WHO European Region, experts, patients and communities affected by the disease. The plan takes into account new diagnostic techniques, patient-centred models of care and services tailored to special populations. It includes six strategic directions, such as collaboration on more effective drugs, vaccines and testing, and seven areas of intervention, such as improving access to testing and treatment.

The areas of intervention of this new action plan are aligned with and have the same aim as the Global Plan to Stop TB 2011-2015 [4] and the World Health Assembly resolution [5] on prevention and control of $M / X D R-T B$ : universal access to diagnosis and treatment of $M / X D R-T B$.

The targets set by the new action plan, to be achieved by the end of 2015 , are:

- to decrease by $20 \%$ the proportion of MDR-TB cases among previously treated patients,

- to diagnose at least $85 \%$ of estimated MDR-TB cases,

- to treat successfully at least $75 \%$ of patients notified as having MDR-TB.

If fully implemented, the plan is expected, by 2015 , to diagnose 225,000 MDR-TB patients within three days of presenting to a healthcare service with TB symptoms, to successfully treat $127,000 \mathrm{MDR}$-TB patients, and to prevent the emergence of 250,000 new MDR-TB and 13,000 new XDR-TB cases. According to WHO Regional Office for Europe, this would interrupt the transmission of MDR-TB and save 120,000 lives.
References

1. World Health Organization (WHO) Regional Office for Europe. European Member States show new resolve in tackling multidrug-resistant TB. Copenhagen: WHO. 14 Sep 2011. Available from: http://www.euro.who.int/en/what-we-publish/ information-for-the-media/sections/latest-press-releases/ european-member-states-show-new-resolve-in-tacklingmultidrug-resistant-tb

2. World Health Organization (WHO) Regional Office for Europe. Consolidated action plan to prevent and combat multidrug- and extensively drug-resistant tuberculosis in the WHO European Region 2011-2015. Copenhagen: WHO EURO. 12-15 Sep 2011. [Accessed 15 Sep 2011]. Available from: http://www.euro. who.int/__data/assets/pdf_file/o007/147832/wd15E_TB_ ActionPlan_111388.pdf

3. World Health Organization (WHO) Regional Office for Europe. Regional Committee: 15 September 2011. Copenhagen: WHO. [Accessed 15 Sep 2011]. Available from: http://www.euro.who.int/en/who-we-are/governance/ regional-committee-for-europe/news/news/2011/9/ regional-committee-15-september-2011

4. World Health Organization (WHO). Stop TB Partnership. The Global Plan to stop TB 2011-2015. Transforming the fight towards elimination of tuberculosis. Geneva: WHO. [Accessed 15 Sep 2011]. Available from: http://www.stoptb.org/assets/ documents/global/plan/TB_GlobalPlanToStopTB2011-2015.pdf

5. Sixty-second World Health Assembly (WHA). Prevention and control of multidrug-resistant tuberculosis and extensively drug-resistant tuberculosis. 8th plenary meeting, 22 May 2009. [Accessed 15 Sep 2011]. Available from: http://apps.who. int/gb/ebwha/pdf_files/A62/A62_R15-en.pdf 